Retrospective Study

\title{
Rates of Lead Migration and Stimulation Loss in Spinal Cord Stimulation: A Retrospective Comparison of Laminotomy Versus Percutaneous Implantation
}

David D. Kim, MD, Rakesh Vakharyia, DO, Henry R. Kroll, MD, and Adam Shuster, DO

From: Departments of Anesthesiology and Pain Medicine, Henry Ford Hospital, Detroit, MI.

Address correspondence: David D. Kim, MD

Henry Ford Hospital I-3 Pain Clinic 2799 West Grand Blvd Detroit, MI

E-mail:

levenor20oo@gmail.com

Disclaimer: There was no external funding in the preparation of this manuscript.

Conflict of interest: None.

Manuscript received: o1/13/2011

Revised manuscript received: o8/29/2011

Accepted for publication: 10/03/2011

Free full manuscript: www.painphysicianjournal.
Background: Neuromodulation has been used to treat neuropathic pain. Leads have been implanted using laminotomy or percutaneous approaches. Laminotomy implantation has been shown to be superior in terms of lead migration when compared to percutaneous implantation. Lead migration has been reported as high as $68 \%$ with the percutaneous approach. Because of this, newer anchors have been developed but not tested in vivo.

Objectives: This study tests the hypothesis that newer anchoring systems have improved lead migration rates for percutaneous leads relative to laminotomy leads to the point of parity. This study also analyzed if factors such as laterality of symptoms, lead type, level of implant and diagnosis affect migration rates.

Study Design: Neurostimulators implanted in the thoracolumbar spine at Henry Ford Hospital between 2006 and 2008 were reviewed for the following: age, sex, diagnosis, lead type, and implant level. Implants were reviewed for the following: age, sex, diagnosis, lead type, implant level, implant method, symptom laterality, loss of stimulation, radiographic lead migration, and time to loss. Loss of capture and lead migration in the laminotomy and percutaneous groups were compared using Fisher's exact test. Variables within each group included: lead type, level of implantation, location of symptoms, and diagnosis. They were compared using Fisher's exact test. Time to loss of stimulation was compared using the Wilcoxon 2-sample test.

Setting: Pain Clinic, Henry Ford Hospital, Detroit, MI.

Results: Laminotomies were performed by a single neurosurgeon and percutaneous implants were performed by a single pain medicine specialist. Percutaneous leads were anchored using Titan (Medtronic Corporation, Minneapolis, MN) anchors. Loss of capture was $24 \%$ laminotomy and $23 \%$ percutaneous with no significant difference between the 2 groups $(P=0.787)$. Radiographic evidence of migration was $13.63 \%$ percutaneous and $12.67 \%$ laminotomy with no significant difference ( $P$ $=0.999$ ). The average days to loss of stimulation for the laminotomy versus percutaneous were as follows: 124.82 and 323.6 which were not statistically significant. There was no statistical difference in the days to loss of capture between the groups $(P=0.060)$. There was no significant difference between unilateral or bilateral symptoms in loss of capture within either group $(P=0.263, P=0.326)$. There was not enough data to do comparisons by diagnosis. Comparisons of loss of capture based on electrode type was not significant in either group $(P=0.687, P=0.371)$. The effect of the spinal level on the lack of recapture rates was not able to be calculated due to the number of levels.

Limitations: Retrospective study.

Conclusion: Rates of stimulation loss and radiographic lead migration are similar for both laminotomy and percutaneous implantation. Time to loss of stimulation was not statistically different in either group, although there was a trend toward laminotomy leads migrating earlier. Lead type and laterality of symptoms do not affect lead migration rates. The effect of the level of implant and diagnosis was indeterminate.

Key words: Neuromodulation, spine, stimulation, complication, migration, pain

Pain Physician 2011; 14:513-524

www.painphysicianjournal.com 


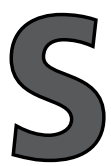
pinal cord stimulation (SCS) has been used to treat pain from a variety of pain conditions since Shealy et al (1) proposed its use based on Melzak and Walls' (2) gate control theory of pain where stimulation of faster lower threshold nerve fibers effectively blocks slower pain fibers. Its effectiveness has been demonstrated in randomized prospective trials and systematic reviews for a variety of conditions including failed back surgery syndrome (FBSS), peripheral neuropathies, complex regional pain syndrome (CRPS), and postamputation pain (3-25). Initial placements of the first electrodes were subdural with the complication of cerebral spinal fluid leak and fibrosis (1). Epidural placement has been the preferred location for SCS since the findings of Burton (25) which found comparable results. The most common complication limiting efficacy has been loss of pain coverage due to lead migration. A 2004 metaanalysis of 2,700 implants by Cameron (26), covering 20 years of literature, demonstrated lead migration as being the most common complication with a migration rate of $13.2 \%$ and unwanted stimulation suggestive of subtle lead displacement of $2.4 \%$. Percutaneous and laminotomy methods for implantation have been used. Earlier studies by Le Doux et al (27) using laminotomy leads and Racz et al (30) using quadrapolar percutaneous leads noted high migration rates of $31.3 \%$ and $69.2 \%$ respectively. The superiority of laminotomy leads was further suggested by North et al (29) in a 1993 retrospective review of 320 patients over 20 years. The authors reported migration rates to be greater in percutaneous leads after one year with overall rates approaching $22 \%$ at 17 years. The study was not clear if the percutaneous lead group and laminotomy lead group had the same diagnosis and had equal distribution in terms of the implant's spinal level. The study was not specific for rates of radiographic proven migration versus loss of concordant stimulation. Rosenow et al (30), in their review of failure modes in implants performed from 1998 through 2002, found no differences in laminotomy versus percutaneous lead implant, but their study had a low number of laminotomy leads with percutaneous leads having a much higher percentage of patients with implantation in the problematic cervical level, which has been reported to have higher technical failure rates (30-32). Newer leads, multiple lead configurations, complex programming and anchoring systems such as the Titan anchor (Medtronic Corporation, Minneapolis, MN) have been used recently. Along with multiple developments, other techniques and consequences of stimulation have been described (33-39).

Our study sought to test the hypothesis that lead migration rates, as proven radiographically, are equal in percutaneous versus laminotomy style leads given present SCS technology. We also wanted to see if there are certain characteristics such as symptom laterality, diagnosis, lead type, depression, and the implant's specific level are predictive for current spinal cord stimulator technology failures.

\section{Methods}

Neurostimulators implanted in the thoracolumbar spine at Henry Ford Hospital in Detroit Michigan from 2006 to 2008 were reviewed for the following: age, sex, diagnosis, lead type, implant level, implant method, symptom laterality (unilateral or bilateral), loss of stimulation, radiographic evidence lead migration, and time to loss. Records were retrieved from the electronic record. All percutaneous leads were implanted by the first author through the department of anesthesiology (pain medicine division) at Henry Ford Hospital with Titan anchors (Medtronic Corporation, Minneapolis, MN) used at implant. All laminotomy leads were implanted by a single neurosurgeon at Henry Ford Hospital. All implanted leads were from a single manufacturer (Medtronic Corporation, Minneapolis MN). Prior to implantation, patients underwent clearance with a neuropsychologist and underwent spinal cord stimulator trial via percutaneous placement of epidural spinal cord stimulator leads using Pisces-Quad or Pisces-Octad leads (Medtronic Corporation, Minneapolis, MN) for 5 days. Patients who underwent percutaneous implant with bilateral symptoms had 2 leads placed. Patients who derived $>50 \%$ relief underwent implant. Following the pain clinic's protocol, patients implanted by neurosurgery or anesthesia's pain service were followed up in the anesthesia pain clinic for postoperative care and stimulator reprogramming. Patients who had a loss of concordant stimulation had radiographs taken to rule out evidence of lead migration. The radiographs were read by a radiologist at Henry Ford Hospital and were reviewed by the implanting physician. Rates of loss of concordant stimulation capture and radiographic evidence of lead migration in the laminotomy and percutaneous groups were compared using Fisher's exact test. Variables within each group, such as lead type, level of implantation, location of symptoms, and diagnosis, were compared using Fisher's exact test. The length of time to loss of concordant stimulation despite repro- 
gramming was compared between the laminotomy and percutaneous groups using the Wilcoxon 2-sample test. Student's t-test was used to test for an age/gender difference between the 2 groups while the chi-square test was used to calculate the $P$ value. The electronic medical records were reviewed for evidence of a new onset of depression or worsening of depression such as clinician or patient report, referral to psychiatry, an increase or change in antidepressants, or a new addition of medications for depression since implant and prior to reports of loss of stimulation. The records were also reviewed to see if the patients who maintained concordant stimulation found the stimulation no longer pleasant or painful. Fisher's exact test was used to evaluate any differences based on the previously mentioned parameters.

\section{RESULTS}

\section{Demographics}

A total of 71 patients had surgical implantation with laminotomy leads and 22 patients had percutane- ous implantation during the time period studied. In the laminotomy group $70 \%(n=50)$ were female and $30 \%(n=21)$ male. In the percutaneous group $77 \%$ ( $n$ $=17)$ were female and $23 \%(n=5)$ were male (Table 1$)$. No significant gender difference was noted between the 2 groups $(P=0.5316)$. The average age in the laminotomy group was 55.4 versus 62.2 in the percutaneous group (Table 1). The percutaneous group was significantly older than the laminotomy group $(P=0.0258)$. The 2 study groups had comparable numbers of patients with bilateral symptoms; the laminotomy group had $43.95 \%$ with bilateral symptoms versus $54.54 \%$ in the percutaneous group. The levels implanted in the laminotomy group ranged from T6 to T12 with the most at T10 $(n=26)$ (Fig. 1). The levels implanted in the percutaneous group ranged from T6 to L1 with the most at T8 ( $n=9$ ) (Fig. 2). FBSS was the diagnosis for the majority of those in the laminotomy group; the majority of the percutaneous group had a diagnosis of lumbar radiculopathy (Figs. 3-4). One-half of the percutaneous group received Pisces-Quad leads; the other

Table 1. Age and gender.

\begin{tabular}{|c|c|c|c|c|c|}
\hline \hline \#Variable & Response & $\begin{array}{c}\text { All } \\
(\mathbf{n}=\mathbf{9 3})\end{array}$ & $\begin{array}{c}\text { Surgical } \\
(\mathbf{n}=\mathbf{7 1})\end{array}$ & $\begin{array}{c}\text { Percutaneous } \\
(\mathbf{n}=\mathbf{2 2})\end{array}$ & P value \\
\hline Age & N mean (SD) & $9357.0(12.6)$ & $7155.4(12.3)$ & $22 \quad 62.2(12.3)$ & $0.0258^{*}$ \\
\hline \multirow{2}{*}{ Gender } & Female & $67(72 \%)$ & $50(70 \%)$ & $17(77 \%)$ & 0.5316 \\
\cline { 2 - 7 } & Male & $26(28 \%)$ & $21(30 \%)$ & $5(23 \%)$ & \\
\hline
\end{tabular}

* The student's t-test
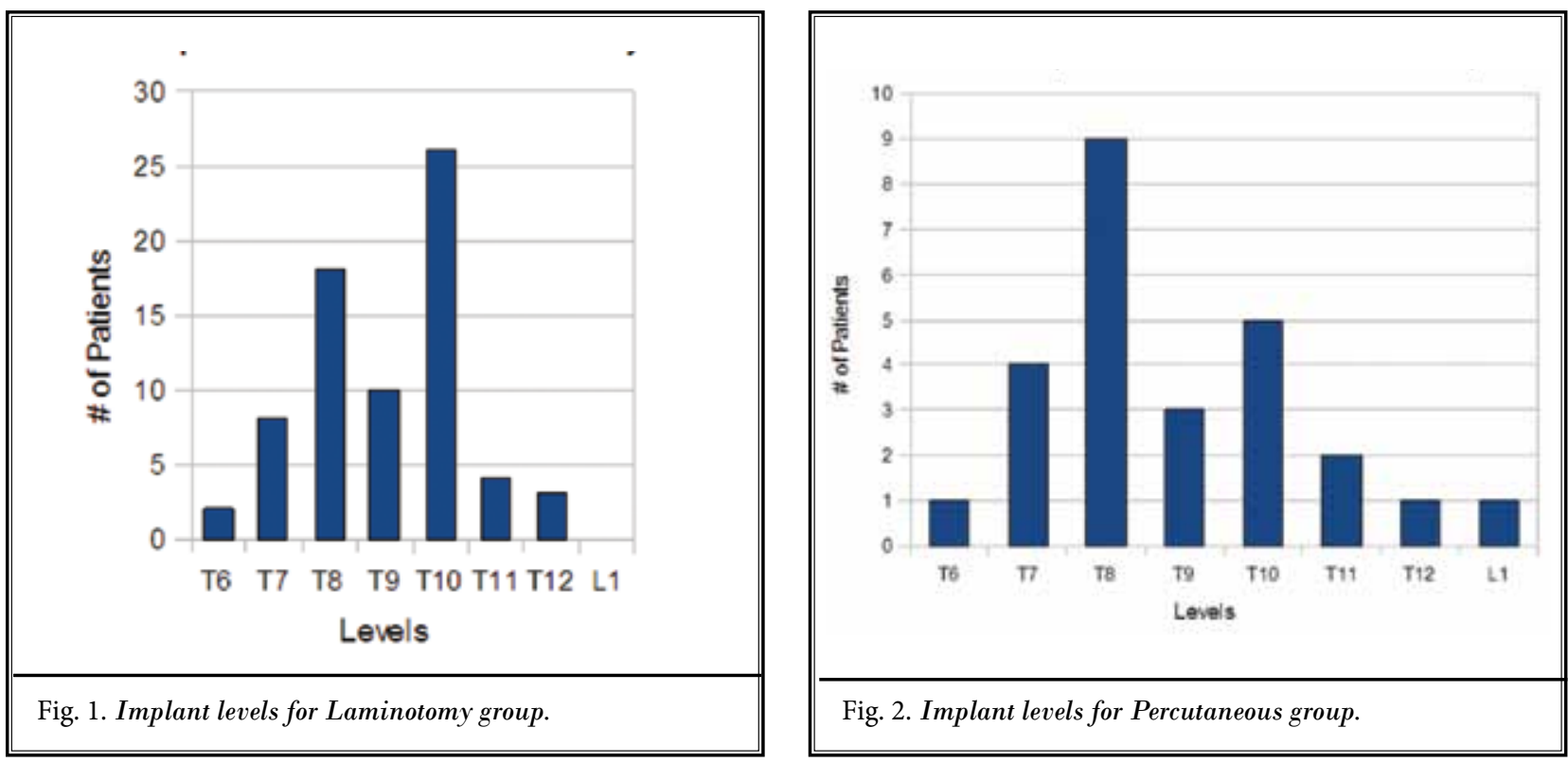

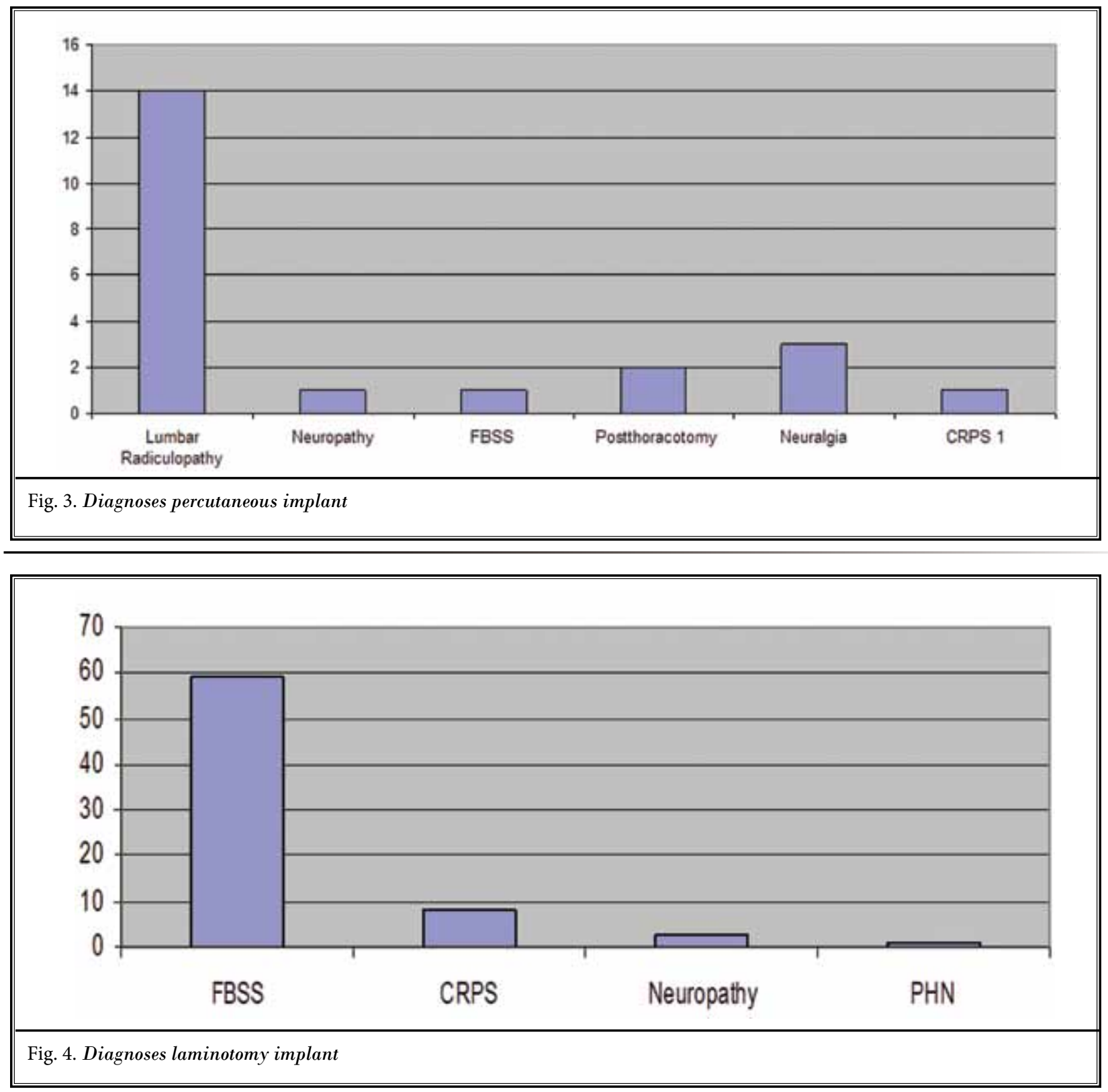

half, Pisces-Octad (Medtronics Corp., Minneapolis, MN) leads. The leads used in the laminotomy group were as follows: Resume TL 12.7\% ( $n=9)$, Specify 39.4\% ( $n=$ 28), Specify (565) $22.5 \%(n=16)$, and Specify (Hinged) $25.4 \%(n=18)$.

Percentage Loss of Concordant Stimulation and Radiographic Evidence of Lead Migration

Loss of concordant stimulation despite reprogramming was $24 \%(n=17)$ in the laminotomy group versus $23 \%(n=5)$ in the percutaneous group without a significant difference in loss rates between the 2 groups $(P=0.787$ ) (Table 2 ). Thoracolumbar radiographs were performed on 16 of the 17 laminotomy group patients who lost coverage with $50 \%$ showing definite lead migration (Table 3) (Figs. 5-6). Radiographs were performed on all 5 patients who lost concordant stimulation in the percutaneous group with $60 \%$ showing radiographic evidence of lead migration (Table 3). The differences between the 2 groups 
were not significant $(P=0.999)$. All patients who lost coverage had functional leads and an internal pulse generator with normal impedances on telemetry. The average time to loss of capture of concordant stimulation for the laminotomy versus percutaneous group was 124.8 days versus 304.8 days respectively (Table
4). The difference, however, was not significant $(P=$ 0.060 ).

The Effect of Level of Implant, Laterality of Symptoms, Diagnosis, and Lead Type on Percentage Loss of Concordant Stimulation

Table 2. Lack of recapture of concordant stimulation by treatment group.

\begin{tabular}{|c|c|c|c|c|}
\hline \multirow{2}{*}{ \#Variable } & Response & $\begin{array}{c}\text { Laminotomy } \\
(\mathbf{n}=\mathbf{7 1})\end{array}$ & $\begin{array}{c}\text { Percutaneous } \\
(\mathbf{n}=\mathbf{2 2})\end{array}$ & P value \\
\hline \multirow{2}{*}{ Recapture } & No & $17(24 \%)$ & $5(23 \%)$ & $0.787^{*}$ \\
\cline { 2 - 5 } & Yes & $54(76 \%)$ & $17(77 \%)$ & \\
\hline
\end{tabular}

* Fisher's exact test

Table 3. Radiographic evidence of lead migration by treatment group.

\begin{tabular}{|c|c|c|c|}
\hline Variable & Laminotomy $(\mathbf{n}=\mathbf{1 6})$ & Percutaneous $(\mathbf{n}=\mathbf{5})$ & P value \\
\hline Yes & $8(50 \%)$ & $3(60 \%)$ & $0.999^{*}$ \\
\hline No/Indeterminate & $8(50 \%)$ & $2(40 \%)$ & \\
\hline
\end{tabular}

* Fisher's exact test
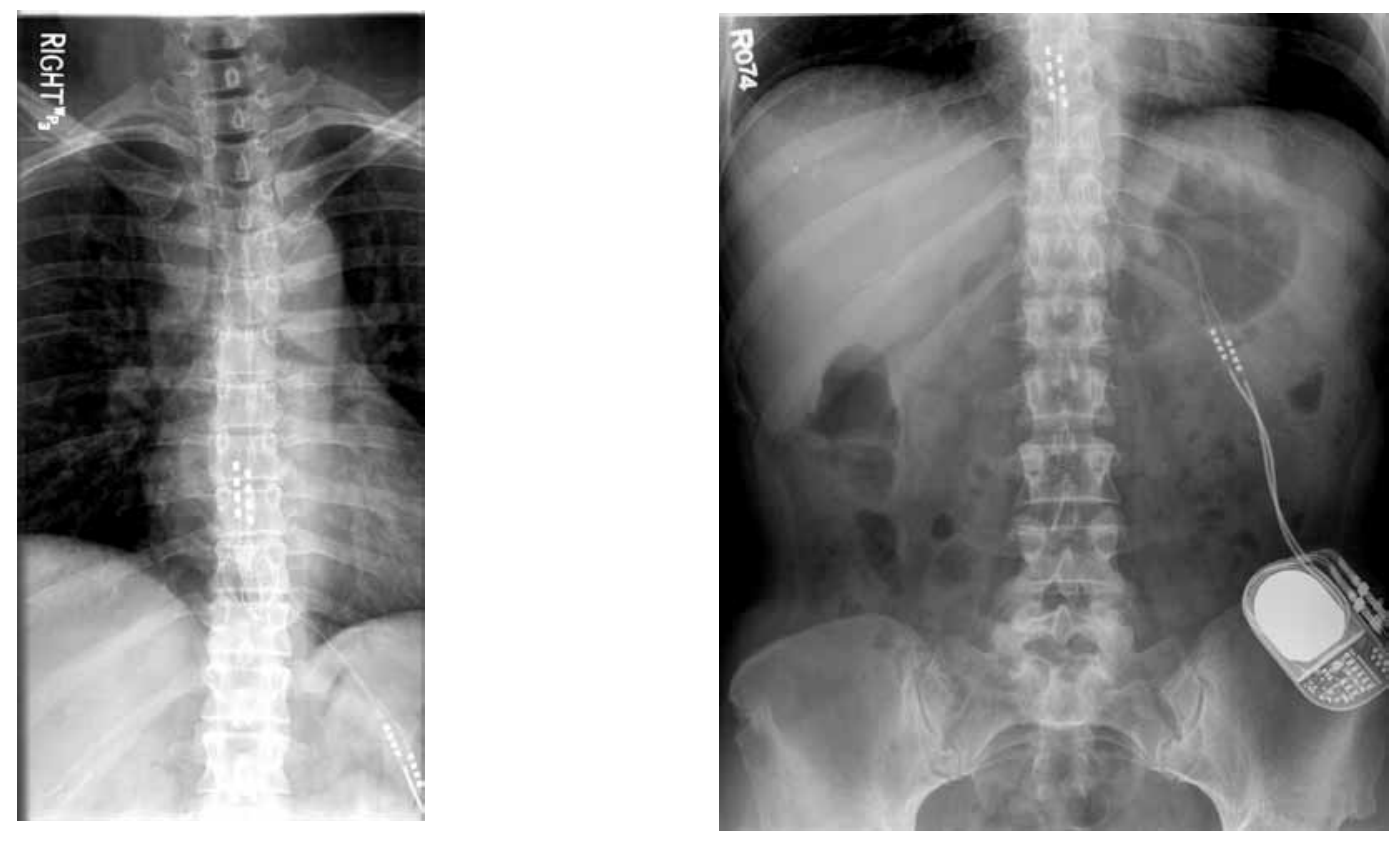

Fig. 5. Left: Subject 1 radiograph at baseline. Right: Subject 1 radiograph showing inferior migration 

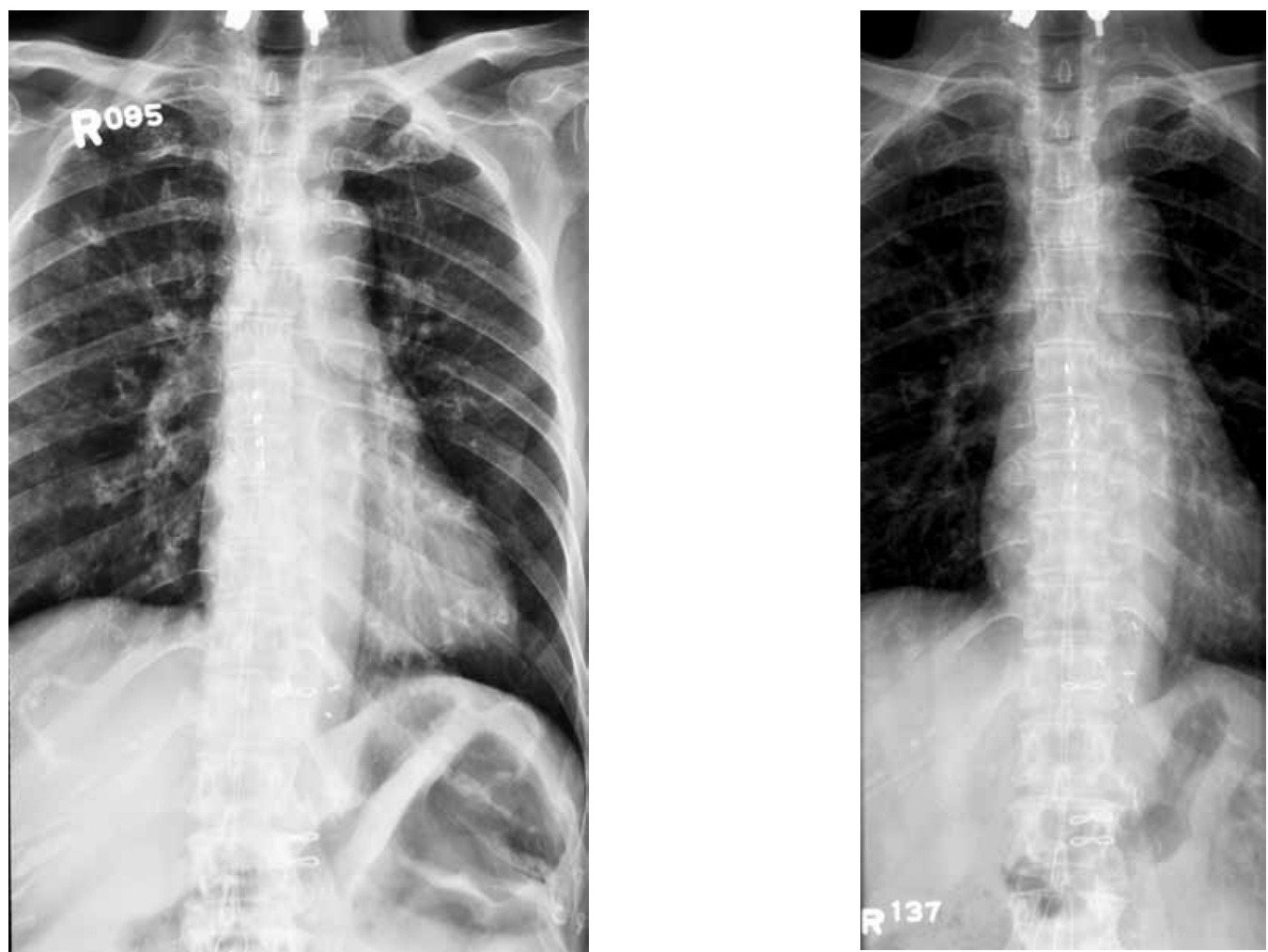

Fig. 6. Left. Subject 2 radiograph at baseline. Right: Subject 2 radiograph showing inferior migration

Table 4. Time to loss of concordant stimulation (days) by treatment group.

\begin{tabular}{|c|c|c|c|}
\hline Group & n & Mean (SD) & P value \\
\hline Laminotomy & 17 & $124.8(135.4)$ & $0.060^{*}$ \\
\hline Percutaneous & 5 & $304.8(328.9)$ & \\
\hline
\end{tabular}

In the laminotomy group, 3 (33\%) with Resume TL had lack of recapture compared to $8(29 \%)$ with Specify, $3(19 \%)$ with Specify 565, and $3(17 \%)$ with Specify Hinged. In the percutaneous group, patients either had Pisces-Octad and Pisces-Quad leads. Comparisons of recapture rates among these laminotomy and percutaneous electrode groups were not significant $(P=0.687, P=0.371$ ) (Tables 5,6$)$. In the laminotomy group, the majority of patients had implants in T10 (n $=26)$ but only $3(12 \%)$ had lack of recapture. Among patients with implants in T8 $(n=18), 7(39 \%)$ had lack of recapture. The effect of the spinal level on the lack of recapture rates is not able to be calculated due to multiple counts of 0 and the large number of levels. In the laminotomy group, the majority of patients were post laminectomy $(n=59)$ (Table 7$)$. Of these, $11(19 \%)$ had a lack of recapture. In the percutaneous group, the majority of patients had lumbar radiculopathy ( $\mathrm{n}$ = 15) (Table 8). Among these patients, 2 (13\%) had a lack of recapture. There are not enough data to do comparisons and groups would need to be condensed. In the laminotomy group, among those with bilateral symptoms, $12(30 \%)$ had a lack of recapture compared to $5(16 \%)$ of those with unilateral symptoms. In the percutaneous group, among those with bilateral placement, one $(8 \%)$ had a lack of recapture compared to 
Rates of Lead Migration in Spinal Cord Stimulation

Table 5. Effect of electrode type on lack of recapture rates, Laminotomy Group.

\begin{tabular}{|c|c|c|c|}
\hline & Lack of recapture $(\mathbf{n}=\mathbf{1 7})$ & Recapture (n = 54) & P -value \\
\hline Resume TL & $3(33 \%)$ & $6(67 \%)$ & $0.687^{*}$ \\
\hline Specify & $8(29 \%)$ & $20(71 \%)$ & \\
\hline Specify 565 & $3(19 \%)$ & $13(81 \%)$ & \\
\hline Specify Hinged & $3(17 \%)$ & $15(83 \%)$ & \\
\hline
\end{tabular}

${ }^{*}$ Fisher's exact test

Table 6. Effect of electrode type on lack of recapture rates, Percutaneous Group.

\begin{tabular}{|c|c|c|c|}
\hline & Lack of recapture (n= 5) & Recapture (n = 22) & P -value \\
\hline Octad & $2(13 \%)$ & $14(88 \%)$ & $0.3705^{*}$ \\
\hline Quad & $3(27 \%)$ & $8(73 \%)$ & \\
\hline
\end{tabular}

* Fisher's exact test

Table 7. Effect of diagnosis on lack of recapture rates, Laminotomy Group.

\begin{tabular}{|l|c|c|}
\hline & $\begin{array}{c}\text { Lack of } \\
\text { recapture (N=17) }\end{array}$ & $\begin{array}{c}\text { Recapture } \\
(\mathbf{n = 5 4 )}\end{array}$ \\
\hline CRPS & $5(63 \%)$ & $3(38 \%)$ \\
\hline Lumbar radiculopathy & 0 & 0 \\
\hline Post-herpetic neuralgia & 0 & $1(100 \%)$ \\
\hline Neuropathy & $1(33 \%)$ & $2(67 \%)$ \\
\hline FBSS & $11(19 \%)$ & $48(81 \%)$ \\
\hline Post thoracotomy & 0 & 0 \\
\hline
\end{tabular}

$4(29 \%)$ of those with unilateral placement (Tables 9, 10). There was not a statistically significant difference between unilateral or bilateral placement in the lack of recapture rates in either the laminotomy group or the percutaneous group (Table 8).

\section{Depression and Loss of Stimulation Rates}

None of the patients who maintained concordant stimulation reported unpleasant stimulation. Evidence of increased depression was seen in $8.6 \%(n=8)$ of all patients. Five of the 8 patients with increased depression reported a loss of concordant stimulation. Four out of 5 of those patients had no radiographic evidence
Table 8. Effect of diagnosis on lack of recapture rates, Percutaneous Group.

\begin{tabular}{|l|c|c|}
\hline \hline & $\begin{array}{c}\text { Lack of } \\
\text { recapture } \\
(\mathbf{n}=\mathbf{5})\end{array}$ & $\begin{array}{c}\text { Recapture } \\
(\mathbf{n = 2 2})\end{array}$ \\
\hline CRPS & $1(50 \%)$ & $1(50 \%)$ \\
\hline Lumbar radiculopathy & $2(13 \%)$ & $13(87 \%)$ \\
\hline
\end{tabular}

of lead migration. The probability of those with depression losing concordant stimulation (63\%) was significantly higher compared to the probability of those without depression losing stimulation $(20 \%)(P=0.017)$. The odds ratio of losing stimulation if depressed versus not depressed was 6.67 with a $95 \%$ confidence interval $(1.45,30.69)$. The probability of those with depression having a loss of stimulation with no radiographic migration $(80 \%)$ was not significantly different than those without depression (38\%) $(P=0.149)$. The odds ratio of those with depression with loss and no radiographic migration versus those without depression was 6.67 with a $95 \%$ confidence interval $(0.6,74.51)$. 
Pain Physician: November/December 2011; 14:513-524

Table 9: Effect of unilateral/bilateral placement on lack of recapture rates, Laminotomy Group.

\begin{tabular}{|l|c|c|c|}
\hline & Lack of recapture $(\mathbf{n}=\mathbf{1 7})$ & Recapture $(\mathbf{n}=\mathbf{5 4})$ & P -value \\
\hline Bilateral & $12(30 \%)$ & $28(70 \%)$ & $0.263^{*}$ \\
\hline Unilateral & $5(16 \%)$ & $26(84 \%)$ & \\
\hline
\end{tabular}

${ }^{*}$ Fisher's exact test

Table 10. Effect of unilateral/bilateral symptoms on lack of recapture rates, Percutaneous Group

\begin{tabular}{|l|c|c|c|}
\hline & Lack of recapture $(\mathbf{n}=\mathbf{5})$ & Recapture $(\mathbf{n}=\mathbf{2 2})$ & P value \\
\hline Bilateral & $1(8 \%)$ & $12(92 \%)$ & $0.326^{*}$ \\
\hline Unilateral & $4(29 \%)$ & $10(71 \%)$ & \\
\hline
\end{tabular}

* Fisher's exact test

\section{Discussion}

\section{Improvements in Migration Rates}

The rates of percutaneous lead migration in this present study has shown improvement over the earlier 1989 study by Racz (28) who reported rates of $69 \%$ in 26 patients who underwent implant. Twenty-five of the patients had thoracolumbar implantation with the most common direction of migration anterolateral. Only a minority of lead migration could be detected by radiographs as in our present study. The rates of migration reported by Racz are in stark contrast to a 1991 study by Le Doux (27) who placed Resume laminotomy leads in the thoracic level for FBSS and reported $31.25 \%$ rates of lead migration. Later studies have shown improvement in reported lead migration for both lead types, especially with the introduction of multichannel leads and complex reprogramming $(6,40-49)$. Kumar (30) in 2006 reported overall lead migration over 22 years of $21.5 \%$, although he used both laminotomy and percutaneous leads. This was consistent with the migration rates seen in our review, although 49 out of 88 displaced electrodes involved the older Sigma system. North (3) in 1993 further demonstrated the superiority of laminotomy leads in a 20year retrospective study of 320 patients with a mixed diagnosis, although 153 were for FBSS. He reported comparable lead migration at one year. After one year the percutaneous leads continued to migrate with a cumulative rate of $22 \%$ at 17 years. This time course difference was also seen in our present study with laminotomy leads losing concordant stimulation much earlier compared to percutaneous leads. Since only a minority of the radiographs showed definite lead migration, one may speculate that very subtle movements can affect stimulation, and the relative greater scar tissue formation with surgical implantation may play a role in earlier migration in surgical implantation. What was not seen was a worsening of overall lead migration after one year with the percutaneous leads; ultimately, there were overall higher migration rates with percutaneous leads. The one limitation of their review may be the fact out of the 226 percutaneous lead implants, 131 involved monopolar or bipolar leads, which have less flexibility in reprogramming recapture. Alo et al (41) in 1998 reported revision rates of only $3.8 \%$ using an 8-electrode lead and complex programming. Mironer et al (43) in 2008 reported marked improvement in revision rates of $4 \%$ using a single midline percutaneous 8-contact electrode for low back pain in a retrospective review of 56 patients.

\section{Laminotomy versus Percutaneous Implantation}

Only a few small studies have directly compared surgical versus percutaneous implantation and those that did were not specifically looking at migration rates as a primary goal. Villavicencio et al (45) in 2000 published outcomes in 27 patients implanted with spinal cord stimulators from 1992 to1998 for low back pain. Fifteen received percutaneous implant with PiscesQuad and 12 received surgical implantation with Resume leads. The laminotomy leads demonstrated better pain control. Lead "displacement" rates were high for both techniques. Repositioning was required for $58 \%$ 
of laminotomy leads and $60 \%$ of percutaneous leads (45). North et al (46) performed a small randomized controlled trial comparing percutaneous and laminotomy leads in 2005 with 12 patients having Resume leads placed surgically versus 12 percutaneous Pisces-Quad leads placed for lumbar failed back syndrome. They reported greater success as defined by patient satisfaction and $>50 \%$ reduction of pain, but this discrepancy disappeared at a 2.9 year follow-up. No lead migration, however, was seen in either group (45). Rosenow et al (30) published a retrospective review of failure modes in spinal cord stimulation hardware implanted from 1998 to 2002. A total of 289 implants were reviewed with 176 performed for CRPS, 182 for FBSS, and the rest being for a multitude of diagnoses. Eighty percent were percutaneous Pisces-Quad or Quad Plus; 20\% were laminotomy Resume or Specify leads. Thoracic level implants numbered 212 and cervical level implants numbered 102 . They reported a migration rate of $12 \%$ in the percutaneous group versus $11.4 \%$ in the laminotomy group with no statistical analysis performed. They also reported "poor coverage" rates separate from the migration rate as being $12.3 \%$ in the percutaneous group versus $10.3 \%$ in the surgical group (30). As our study showed, only $50 \%-60 \%$ of the time can radiographic evidence of migration be detected in patients who lose concordant stimulation. When combining migration and lack of coverage rates in Rosenow's study, the results show a combined loss of concordant stimulation for the percutaneous group of $24.3 \%$ and for the laminotomy group of $21.7 \%$ (30). These are similar to the results in our present study. Several studies have, however, shown the advantages of laminotomy leads beyond better pain control. Laminotomy leads have been reported to cause more comfortable stimulation with less dorsal root stimulation (43-46). They may also have the advantage of better overlap rating, overlap calculation, and amplitude requirement according to North et al $(44,46,47)$. The amplitude advantage may be less given the introduction of newer rechargeable internal pulse generators.

\section{Factors Affecting Lead Migration and Loss of Concordant Stimulation}

The spinal level of implantation has been reported to affect migration with the cervical region reported to have higher revision issues and migration $(27,45)$. Our study concentrated on thoracolumbar levels so an equivalent comparison could be performed. Rosenow et al (30), in their retrospective analysis of failure modes, also compared higher rates for all failures between the diagnoses of CRPS and FBSS. Part of the difference could be explained by the different spinal levels of implant, as discussed previously. Due to the multiple number of diagnoses and multiple different individual levels implanted, it was difficult to draw a conclusion (30). The lead type, based on the configuration and number of leads, however, did not affect the lack of recapture rates or radiographic migration rates. This is consistent with Rosenow's previously mentioned review (30). The laterality of symptoms to be covered by stimulation also did not significantly impact complications. During the writing of this manuscript, we were informed by Medtronic of a recall of the Titan anchor due to delamination of the metallic clamps from the silicone sleeve. One could speculate if the migration rates for percutaneous leads might not have been lower or if a direct suture technique as proposed by Kreis et al (48) in 2009 was used instead of using the manufacturer's anchoring systems.

The literature on the role of depression in the efficacy of SCS was recently reviewed by Sparke et al (49). They reported 3 studies reporting the negative impact of pretrial depression on trial success. They reported the negative effect of depression on SCS's long-term efficacy. They noted, however, that none of the previous studies distinguished if depression was present before the SCS implantation or developed afterward. Two studies have actually reported improvement in depression with SCS, presumably due to better pain control $(50,51)$. In the present study there was worsening depression with a patient who lost concordant stimulation. There was, however, no significant relation between depression and having a loss of stimulation without radiographic migration. Based on the previous findings, one may hypothesize that the depression was due to inadequate pain relief and not the cause for the reports of loss of stimulation.

\section{Possible Causes and Prevention of Loss of Concordant Stimulation Without Radiographic Migration: Neuroplasticity and Epidural Fibrosis}

Roughly $50 \%$ of the patients who lost concordant stimulation showed no definite radiographic migration. Tolerance to stimulation has been described by several authors since the early days of this technology's adoption $(3,52,53)$.Its development is not absolute and may also be diagnosis dependent, as described by Andersen (54) in a 24 month study of spinal cord stimulation for angina pectoris in which no tolerance to stimu- 
lation was noted. There is a lack of literature on the mechanism and prevention of tolerance with SCS. Two possible causes are neuroplasticity and epidural fibrosis. Neuroplasticity has been described in several deafferent pain syndromes, angina, and peripheral vascular disease (55-58). The effects of SCS at the supraspinal level have been reported by Clavo et al (59) where increased cerebrovascular blood flow was demonstrated with cervical stimulation and Schlaier et al (60) who demonstrated changes in cortical excitability. At the infraspinal level, the mechanism of SCS has been shown to involve augmentation of gamma-aminobutyric acid (GABA) and adenosine $(61,62)$. There is evidence of disinhibition of antinociceptive pathways from the periaqueductal grey matter (PAG) leading to release of serotonin and substance $P(63,64)$. One may speculate that tolerance may be due to depletion of these neurotransmitters. This has been described in a correlate to SCS in the form of cortical stimulation.

Hosobuchi (65) reported a case series of subcortical stimulation for intractable pain. He reported tolerance in the PAG and thalamic stimulation, which was reversed with L-tryptophan (precursor to serotonin) and methyldopa respectively (65). Kumar et al (32), however, stated that the use of amitriptyline and L-tryptophan yielded poor results from his experience and speculated about the use of a stimulation holiday to reverse tolerance. North et al (3) found complex programming with multiple channel configurations decreased the loss of stimulation as an overall phenomenon. The intrathecal administration of baclofen (a GABA agonist) has been shown to significantly increase the effects of SCS in both animal and human models $(67,68)$. Both oral and intrathecal use of baclofen may warrant further study in the prevention or reversal of tolerance.

Epidural scarring has also been implicated in the loss of efficacy of SCS $(69,70)$. Nashold et al $(71)$ speculated that tissue reaction around the electrodes he saw on reimplantation and autopsy may be responsible. Reynolds (72) presented a case report of loss of efficacy and need for increased amplitude to achieve stimulation for torticollis. The patient subsequently developed spastic quadriparesis and on re-exploration of the implant site noted dense scar formation around the electrode. Dam-Hieu (73) reported 2 cases of tolerance development followed by cervical cord compression due to delayed lead scarring.

\section{Conclusion}

There has been steady improvement in the rates of loss of concordant stimulation and radiographic lead migration for both percutaneous and laminotomy leads to the point of parity between both methods of implant. Laminotomy leads trended toward an earlier loss of stimulation and migration in our present study. Individual lead type and laterality of symptoms did not affect migration rates. Loss of stimulation could not always be correlated to radiographic migration. This study is still limited by its retrospective nature and the small number of percutaneous compared to laminotomy implants, which limited some of the comparisons and may affect the significance of the results.

\section{ACKNOWLEDGMent}

We would like to thank the editorial board of Pain Physician for review and constructive criticism in improving the manuscript.

\section{References}

1. Shealy CN, Mortimer JT, Reswick JB. Electrical inhibition of pain by stimulation of the dorsal columns: Preliminary clinic report. Anesth Analg 1967; 46:489491.

2. Melba R, Wall PD. Pain mechanisms: A new theory. Science 1965; 150:971-979.

3. North RB, Kid DH, Zahurak M, James CS, Long DM. Spinal cord stimulation for chronic intractable pain: Two decades' experience. Neurosurgery 1993; 32:384395. Outcome of implanted spinal cord stimulation in the treatment of chronic pain: Arachnoiditis versus single root injury and mononeuropathy. Clin J Pain 1989; 5:189-193.

5. Waisbrod H, Gerbershagen HU. Spinal cord stimulation in patients with battered root syndrome. Arch Orthop Trauma Surg 1985; 104:62-69.

6. Burchiel KJ, Anderson VC, Brown FD, Ressler RG, Friedman WA, Pelofsky S,
Weiner RL, Oakley J, Shatin D. Prospective: Multicenter study of spinal cord stimulation for the relief of chronic back pain and extremity pain. Spine 1996; 21:2786-2794.

7 North RB, Kidd DH, Lee MS, Piantadosi S. Spinal cord stimulation versus reoperation for failed back syndrome: A prospective randomized study design. Sterotact Funct Neurosurg 1994; 62:267-272.

8. Ohmeiss DD, Rashbaum RF, Bogdnaffy GM. Prospective outcome evaluation of 
spinal cord stimulation in patients with intractable leg pain. Spine 1996; 21:13441351.

9. North RB, Kidd DH, Campbell JN, Long DM. Dorsal root ganglionectomy for failed back syndrome: A five year followup study. J Neurosurg 1991; 74; 236-242.

10. North RB, Ewend MG, Lawton MT, Kidd $\mathrm{DH}$, Piantadosi S. Failed back syndrome: Five-year follow-up after spinal cord stimulator implantation. Neurosurg1991; 28:692-699.

11. Kemler MA, Barendse GAM, van Kleef M, de Vet HCW, Rijks CPM, Furnee CA, van den Widenberg FAJM. Spinal cord stimulation in patients with chronic reflex sympathetic dystrophy. N Engl J Med 2000; 343: 618-624.

12. North RB, Kidd DH, Farrokhi F, Piantadosi SA. Spinal cord stimulation versus repeated lubrosacral spine surgery for chronic pain: A randomized controlled trial. Neurosurgery 2005; 56:98-107.

13. Graybill J, Conermann T, Kabazie AJ, Chandy S. Spinal cord stimulation for treatment of pain in a patient with post thoracotomy pain syndrome. Pain Physician 2011; 14:441-445.

14.. Lowry AM, Simopoulos TT. Spinal cord stimulation for the treatment of chronic knee pain following total knee replacement. Pain Physician 2010; 13:251-256.

15. McJunkin TL, Wuollet AL, Lyncy PJ. Sacra nerve stimulation as a treatment modality for intractable neuropathic testicula pain. Pain Physician 2009; 12: 991-995..

16. Kumar K, Taylor RS, Jacques L, Eldabe S, Meglio M, Molet J, Thomson S, O'Callaghan J, Eisenberg E, Milbouw G, Buchser E, Fortini G, Richardson J, North RB. The effects of spinal cord stimulation in neuropathic pain are sustained: A 24-month follow-up of the prospective randomized controlled multicenter trial of the effectiveness of spinal cord stimulation. Neurosurgery 2008; 63:762-770.

17. Kumar K, Taylor RS, Jacques L, Eldabe S, Meglio M, Molet J, Thomson S, O'Callaghan J, Eisenberg E, Milbouw G, Buchser E, Fortini G, Richardson J, North RB. Spinal cord stimulation versus conventional medical management for neuropathic pain: A multicentre randomized controlled trial in patients with failed back surgery syndrome. Pain 2007; 132:179-188.

18. Kemler MA, De Vet HC, Barendse GA, Van Den Wildenberg FA, Van Kleef MV. The effect of spinal cord stimulation in patients with chronic reflex sympathetic dystrophy: Two years' follow-up of the randomized control trial. Ann Neurol
2004; 55:13-18.

19. Frey ME, Manchikanti L, Benyamin RM, Schultz DM, Smith HS, Cohen SP. Spinal cord stimulation for patients with failed back surgery syndrome: A systematic review. Pain Physician 2009; 12:379-397.

20. Manchikanti L, Boswell MV, Singh V, Benyamin RM, Fellows B, Abdi S, Buenaventura RM, Conn A, Datta S, Derby R, Falco FJE, Erhart S, Diwan S, Hayek SM, Helm S, Parr AT, Schultz DM, Smith HS, Wolfer LR, Hirsch JA. Comprehensive evidence-based guidelines for interventional techniques in the management of chronic spinal pain. Pain Physician 2009; 12:699-802.

21. Manchikanti L, Boswell MV, Datta S, Fellows B, Abdi S, Singh V, Benyamin RM, Falco FJE, Helm S, Hayek S, Smith HS. Comprehensive review of therapeutic interventions in managing chronic spinal pain. Pain Physician 2009; 12:E123-E198.

22. Manchikanti L, Datta $S$, Gupta $S$, Munglani R, Bryce DA, Ward SP, Benyamin RM, Sharma ML, Helm II S, Fellows B, Hirsch JA. A critical review of the American Pain Society clinical practice guidelines for interventional techniques: Part 2. Therapeutic interventions. Pain Physician 2010; 13:E215-E264.

23. Manchikanti L, Falco FJE, Boswell MV, Hirsch JA. Facts, fallacies, and politics of comparative effectiveness research: Part 2. Implications for interventional pain management. Pain Physician 2010; 13:E55-E79.

24. McJunkin TL, Wuollet AD, Lynch PJ. Sacral nerve stimulation as a treatment modality for intractable neuropathic testicular pain. Pain Physician 2009; 12:991995 .

25. Burton C. Dorsal column stimulation: Optimization of application. Surg Neurol 1975; 4:171-176.

26. Cameron T. Safety and efficacy of spinal cord stimulation for treatment of chronic pain: A 20 year literature review. J Neurosurg 2004; 100:254-267.

27. Le Doux MD, Langford L. Spinal cord stimulation for failed back syndrome. Spine 1991; 18:191-194.

28. Racz GB, McCarron RF, Talboys P. Percutaneous dorsal column stimulator for chronic pain control. Spine 1989; 14:1-4.

29. North RB, Ewend MG, Lawton MT, Piantadosi S. Spinal cord stimulation for chronic intractable pain: Superiority of "multichannel" devices. Pain 1991; 44:119130.

30. Rosenow JM, Stanton-Hicks M, Rezai AR, Henderson JM. Failure modes of spinal cord stimulator hardware. ] Neurosurg Spine 2006; 5:183-190.

31. Broggi G, Servello D, Dones I, Carbone G. Italian multicentric study on pain treatment with epidural spinal cord stimulation. Stereotact Funct Neursurg 1994; 62:273-278.

32. Kumar K, Hunter G, Demeria D. Spinal cord stimulation in the treatment of chronic benign pain: Challenges in treatment planning and present status, a 22year experience. Neurosurg 2006; 58:481493.

33. Falco FJE, Berger J, Vrable A, Onyewu O, Zhu J. Cross talk: A new method for peripheral nerve stimulation. An observational report with cadaveric verification. Pain Physician 2009; 12:965-983.

34. Schade CM, Schultz DM, Tamayo N, lyer S, Panken E. Automatic adaption of neurostimulation therapy in response to changes in patient position: Results of the posture responsive spinal cord stimulation (PRS) research study. Pain Physician 2011; 14:407-417.

35. Zhu J, Falco FJE, Onyewu OVesga R, , Josephson Y, Husain A, Gutman G. Alternative approach to needle placement in cervical spinal cord stimulator insertion. Pain Physician 2011; 14:195-210.

36. Zhu J, Falco FJE, Onyewu O, Josephson $Y$, Vesga R, Jari R. Alternative approach to needle placement in spinal cord stimulator trial/implantation. Pain Physician 2011; 14:45-53.

37. Wininger KL, Deshpande KK, Deshpande KK. Radiation exposure in percutaneous spinal cord stimulation mapping: A preliminary report. Pain Physician 2010; 13:718.

38. Smith CC, Lin JL, Shokat M, Dosanjh SS, Casthely D. A report of paraparesis following spinal cord stimulator trial, implantation and revision. Pain Physician 2010; 13:357-363.

39. Yearwood TL, Hershey B, Bradley K, Lee D. Pulse width programming in spinal cord stimulation: A clinical trial. Pain Physician 2010; 13:321-335

40. Spincemaille GH, Klomp HM, Steyerberg EW, van Urk $\mathrm{H}$, Habbemma JDF. Technical data and complication of spinal cord stimulation: Data from a randomized trial on cortical limb ischemia. Stereotact Funct Neurosurg 2000; 74:63-72.

41. Alo KM, Yland MJ, Kramer DL, Charnov $\mathrm{JH}$, Redko V. Computer assisted and patient interactive programming of dual octrode spinal cord stimulation in the treatment of chronic pain. Neuromodulation 1998; 1:30-45. 
42. Anderson C. Complications in spinal cord stimulation for treatment of anginal pectoris: Difference in unipolar and multipolar percutaneous inserted electrode. Acta Cardiologica 1997; 52:325-333.

43. Mironer EY, Satterthwaite JR, Lewis EM, Haasis JC, LaTourette PC, Skoloff EM, Diaz RL. Efficacy of a single percutaneous across midline, octrode lead using midline anchoring technique in the treatment of low back and/or lower extremity pain: A retrospective study. Neuromodulation 2008; 11: 286-295.

44. North RB, Olin JC, Kidd DH, Sieracki JN. Spinal cord stimulation electrode design: A prospective randomized comparison of percutaneous and laminotomy electrodes. Poster presented at: 66th Annual Meeting of the American Association of Neurological Surgeons; 1998; Philadelphia, PA.

45. Villavicencio AT, Leveque J, Rubin L. Laminectomy versus percutaneous electrode placement for spinal cord stimulation. Neurosurg 2000; 46:399-456.

46. North RB, Kidd DH, Petrucci L, Dorsi MJ. Spinal cord stimulation electrode design: A prospective randomized control trial comparing percutaneous with laminectomy electrodes: Part II-clinical outcomes. Neurosurgery 2005; 57:990-994.

47. North RB, Lannin A, Hessels R, Cutchis PN. Spinal cord stimulation with percutaneous and plate electrodes: side effects and quantitative comparison. Neurosurg Focus 1997; 2:e3.

48. Kreis PG, Fishman SM, Chau K. Impact to spinal cord stimulator lead integrity with direct loop ties. Pain Med 2009; 10:495-500.

49. Sparkes E, Raphael JH, Duarte RV, LeMarchand K, Jackson C, Ashford RL. A systematic literature review of psychological characteristics as determinants of outcome for spinal cord stimulation therapy. Pain 2010; 150:284-289.

50. Burchiel KJ, Anderson VC, Brown FD, Fessler RG, Friedman WA, Pelofsky S, Weiner RL, Oakley, Shatin D. Prospective, multicenter study of spinal cord stimulation for relief of chronic back and extremity pain. Spine 1996; 21:2786-2794.

51. Jamison RN, Washington TA, Fanciullo G), Ross E, McHugo GJ, Baird JC. Do im- plantable devices improve mood? Comparisons of chronic pain patients with or without an implantable device. Neuromodulation 2008; 11:260-266.

52. Pineda A. Dorsal column stimulation and its prospects. Surg Neurol 1975; 4:157-163.

53. Pineda A. Complications of dorsal column stimulation. J Neurosurg 1978; 48:64-68.

54. Anderson C. Time dependent variation of stimulation requirements in spinal cord stimulation for angina pectoris. Pacing Clin Electrophysiol 1997; 20:359-363.

55. Erdek MA, Statts PS. Spinal cord stimulation for angina pectoris and peripheral vascular disease. Anesthesiol Clin North America 2003; 21:797-804.

56. Flor $\mathrm{H}$, Elbert $\mathrm{T}$, Knecht $\mathrm{S}$, Wienbruch $\mathrm{C}$, Pantev C, Birbaumer N, Larbig W, Taub E. Phantom-limb pain as a perceptual correlate of cortical reorganization following arm amputation. Nature 1995; 482-484.

57. Kreis ZH, Dostrovsky JO. Tasker RR. Plasticity in human somatosensory thalamus as a result of deafferentation. Stereotact Funct Neurosurg 1994; 62:153-163.

58. Dickenson AH. Central acute pain mechanisms. Ann Med 1995; 27:223-227.

59. Clavo B, Robaina F, Catala L, Lloret $M$, Pinar B, Caramés MA, Ruiz A,. Cabezón A, González G, Lara P, Ruiz-Egea E, Hernández MA. Cerebral blood flow increase in cancer patients by applying cervical spinal cord stimulation. Neurocirugia 2007; 18:28-32; discussion 33-35.

6o. Schlaier JR, Eichhammer P, Langguth $B$, Doenitz C, Binder H, Hajak G, Brawanski A. Effects of spinal cord stimulation on cortical excitability in patients with chronic neuropathic pain: A pilot study. Eur J Pain 2007; 11:863-868.

61. Cui JG, O'Connor WT, Ungerstedt U Linderoth, B, Meyersonet BA. Spinal cord stimulation attenuates dorsal horn release of excitatory amino acids in mononeuropathy via GABAergic mechanism. Pain 1997; 73:87-95.

62. Meyerson B, Linderoth B. Mechanism of spinal cord stimulation in neuropathic pain. Neurology Res 2000; 22:285-292.

63. Stiller CO, Linderoth B, O'Connor W, Franck J, Falkenberg T, Ungerstedt U,
Brodinet E. Repeated spinal cord stimulation decreases the extracellular level of gamma-aminobutyric acid in the periaquaductal grey matter of freely moving rats. Brain Res 1995; 699:231-241.

64. Linderoth B, Gazelius B, Franck J, Brodin E. Dorsal column stimulation induces release of serotonin and substance $P$ in the cat dorsal horn. Neurosurgery 1992; 31:289-296.

65. Hosobuchi Y. Subcortical electrical stimulation for control of intractable pain in humans: Report of 122 cases (1970-1984). J Neurosurg 1986; 64:543-553.

66. Cui JG, Linderoth B, Meyerson BA. Effects of spinal cord stimulation on touch evoked allodynia involve GABAergic mechanisms. An experimental study in mononeuropathic rats. Pain 1997; 73:8795.

67. Meyerson BA, Cui JG, Yakhnitsa V, Sollevi A, Segerdahl M, Stiller CO, O'Connor WT, Linderoth B. Modulation of spinal pain mechanisms by spinal cord stimulation and the potential role of adjuvant pharmacotherapy. Stereotact Funct Neurosurg 1997; 68:129-140.

68. Krainick JU, Thoden U, Riechert T. Pain reduction in amputees by long term spinal cord stimulation. Long term followup study over 5 years. ] Neurosurg 1980; 52:346-350.

69. Kumar K, Nath R, Wyant GM. Treatment of chronic pain by epidural spinal cord stimulation: A ten-year experience. J Neurosurg 1991; 75:402-407.

70. Kupers RC, Van der Oever RV, Houdenhove BV, Vanmechelen W, Hepp B, Nuttin B,. Gybels JM. Spinal cord stimulation in Belgium: A nation-wide survey on the incidence, indications, and therapeutic efficacy by the health insurer. Pain 1994; 56:211-216.

71. Nashold BS Jr. Dorsal column stimulation for control of pain: A three year follow up. Surg Neurol 1975; 4:146-147.

72. Reynolds AF, Shetter AG. Scarring around cervical epidural stimulating electrode. Neurosurgery 1983; 13:63-65.

73. Dam-Hieu P, Magro E, Seizeur R, Simon A, Quinio B. Cervical cord compression due to delayed scarring around epidural electrodes used in spinal cord stimulation. J Neurosurg Spine 2010; 12:409-412. 